\title{
Decision-Making under Uncertainty from the Perspective of Cognitive and Behavior
}

\author{
Siska Sasmita \\ Graduate student of Department of Public Policy and Management, \\ Faculty of Social and Political Sciences, Universitas Gadjah Mada \\ siska.sasmita@mail.ugm.ac.id
}

\begin{abstract}
This study aims exploring perspectives contribute to decision making under uncertainty from the public administration point of view. Literature review is used to answer the research question by collecting and analyzing academic article related to the topic, then grouping each into a table based on their similarities. Notion of uncertainty in decision making, indeed, has been elaborated since 1940s, albeit from economics and management related to customer behavior which then transferred quantitatively and transformed into models. Despite the limitation in finding appropriate article in public administration context, result of this research tells us the cognitive perspective and behavior take important contribution to decision making under uncertainty studies. They do not separated firmly since they tend to be a series task or overlapped in certain aspects.
\end{abstract}

Keywords: uncertainty, decision making, decision making under uncertainty, cognitive, behavior

\section{Introduction}

Organization circumstance has not always in a stable, since haphazard nuisance could suddenly attack either from inside or outside organization; naturally or man-made. A hidden time bomb often unpredictable, explode when organization members think all is well. Production system and financial problems are types of internal crisis often faced by business organization, whilst public organization deals with public policy and service crises. These also pertain to man-made crisis for mismanagement, lack of resources, lag of communication and coordination among organization entities. On the other hand, a natural hazard usually seen as an external type of crisis which strike from outside organization but affected organizational environment. A hurricane, landslide, earthquake and tsunami have devastated organization activities. However, we cannot neglect that some crises attack from outside organization, such as political crisis in French Government in 19th century to mid-20th century, 9/11 terrorist attack and 2007-2008 financial crisis, which are categorized as manmade calamity.

Although the organization has already prepared their entities to respond the crisis, it often cannot well-handled since the complex problem during calamity indicated by hyperuncertainty (Farazmand, 2017: 149), uniqueness situation and time pressure (Wenzelburger, König, \& Wolf, 2017). Manager might regularly faceunpredictable condition, however, uncertainty is not normal yet complicated dynamic nature (Sayegh, Anthony, \& Perrewé, 2004: 180). Different pattern of one crisis to another with multiple criteria has affect way in designing alternative. On the other hand, source and type of uncertainty influence probabilistic feature used to design disastercoping strategy and defining possibility of 
occurring event(Su \& Tung, 2014). Hence, the notion of uncertainty plays important roles in decision making (Faraji-Rad \& Pham, 2017: 1).

Uncertainty has defined through a variationspan: uncertainty as characterization of unknown future outcome and its relation to ambiguity (Bailey, 2010: 11); lack of perfect understanding in related to information acquisition (Su \& Tung, 2014); forecast as basis of decision with cost function combining (Reggiani \& Weerts, 2008); making judgment (Tversky \& Kahneman, 1974); as natural randomness (de Kort \& Booij, 2007). Despite the various perspectives interpreting the notion of uncertainty, those argue uncertainty depict unpredictable future situation as consequences of, i.e. lack of information, failed forecast, difficulties in select measuring.

Studies in decision making under uncertainty tend to traditionally explore acute response in crisis: how to make decision aftermath crisis (Boin, Hart, Mcconnell, \& Preston, 2010: 706) whereas the emergency phase is stressed as the core of the crisis (Sun, Ma, \& Zhao, 2016: 3617) due to its high level of uncertainty. The source of uncertainty is promptly to be investigated for supporting crisis decision making (Faraji-Rad \& Pham, 2017: 1; Madani, Read, \& Shalikarian, 2014: 1849) by identify how it affect decision variable(de Kort \& Booij, 2007: 131) regarding effective solution to be made (Wenzelburger et al., 2017). Unfortunately, decision making at a moment before disaster strike has not considerable yet, indeed, the decision at that time surely uncertain. Some researches were exploring decision at disaster emergency pertaining to early warning system scenario (Sobradelo, Martí, Kilburn, \& López, 2015; Grothe-Hammer \& Berthod, 2017), decision support system (de Kort \& Booij, 2007)which transferred into modeling software called Bademo, fuzzy set, DSS, etc.

Since decision making in emergency is a unique process rather than another phase in catastrophes, which could be analyzed through Natural Decision Making (NDM) approach, it is interesting to make a study from relevant perspectives contributed to decision making under uncertainty situation. Author's aim is to specifically investigate the topic from public administration point of view albeit facing difficult consequences.

\section{Method}

This research is being handled through literature study by compiling ideas from journal articles with various disciplines, despite the aim of this study to develop decision making under uncertainty concept from public administration standing point. It is because the author considers position of public administration as a multidiscipline field. Riccucci (2010: 28-29) cites Funtowicz and Ravetz's concept (1992, 1993, 1994) about post-normal science which adopted as public administration paradigm. Post-normal science refers to "approaches that are broader and more inclusive of different epistemic traditions and methodologies." Hence, contribution from another science is useful to develop a complete concept of decision making under uncertainty which compatible to public administration theory and practice. Reaching the goal, author has been investigating articles from: public administration (i.e. Public Administration Review, Public Administration); economics (i.e. Journal of Consumer Research); management (i.e. Human Research Management Review); natural science (i.e. 
Science, Natural Hazard); environmental science (i.e. Stochastic Environmental Research and Risk Assessment).

There is no time limit regarding the article publishing period. Author has collecting dozens articles from 1980s, 1990s, 2000s to trace the developing thoughts in decision making under uncertainty notion. Several articles, in fact, were firstly published in 1970s, indeed these are useful to depict early phases of decision study.

Ideas from the articles are managed into a table to identified stream of each to another. The table informs the author(s) of each article; its sources; the major findings; research method; strength, weakness, opportunity, threat; and unit analysis. This table depicts a tendency for each article whether it is categorized as behavior or cognitive stream. Information served from the table then used to creating pattern for each perspective.

\section{Result and discussion}

\section{Decision making under uncertainty features in politics and public administration science.}

The notion of uncertainty was begun firstly from economics and psychology especially in behavior stream. It can be traced from articles written by Neumann and Morgenstern (1944), Savage (1954), Kahneman and Tversky (1979), Wakker and Tversky (1993). Generally, the articles mention specific attributes: $i$ ) decision making referred by the authors are exist in imagined context due to limited numbers of real situation describing future uncertainty; or not categorized as decision under uncertainty because they tend to be part of probabilistic concept; ii) they have not yet considered how decision makers bear a meaning for 'decision problem'; iii) they have not yet calculate position of non-cognitive aspect, i.e. motivation, intuition, and emotion which were seen as factors contributed to decreasing optimal decision (Tuckett et al., 2015: 219).

While the fields of economics and psychology have developed their idealistic decision models by adopting mathematical facts, for example: using axioms and principles instead of empirical facts, politics and public administration scholars give attention to decision making under uncertainty ideas. There are two main features marked the appearance: Herbert Simon seminal model 'bounded rationality' (1957) and the Essence of Decisionby Graham T. Allison (1967). Simon and his partner in Carnegie Melon build bounded rationality as critics to global rationality of economic man argues that decision maker possess information and computational capacities fully (Allen, 1977: 81). Conversely, Allison's book explains the fact about Cuban Missile crisis from USA Government's point of view.

Simon 'bounded rationality' points out the constraints to perfectly removed uncertainty in environment when implemented rational decision making and obtains correct prediction as well as forms expectations to shape effective decision (Allen, 1977: 82). It also takes account cognitive limitation of decision maker in achieving goals although it then adopts explicitly behavioral stance (Jones, 1999: 299). Bounded rationality in politics and public administration studies mostly used to describe governmental behavior which seen uncertainty do affect outcome of decision (Jones, 1999: 302). 
Allison efforts in describing Cuban Missile between USA under the President John Fitzgerald Kennedy and USSR under the administration of Nikita Kruschev assumes three typical models in decision making under uncertainty: rational policy, organizational process, and bureaucratic politics. There are also three questions Allison need to be answered: $i$ ) why did the Soviet Union decide to place offensive missile in Cuba; ii) why the United States respond to the missile deployment with a blockade; iii) why did the Soviet Union withdraw the missile. The second question seems exclusive as Allison build five hypothesis on it: $i$ ) hypothesis one: bargaining barter; ii) hypothesis two: diverting trap; iii) hypothesis three: Cuban defense; $i v$ ) hypothesis four: Cold war politics; $v$ ) hypothesis five: missile power (Allison, 1971).

Generally, Allison empowers those three models answering the questions. Rational Policy Model argues government as a rational decision maker unit which has a tendency to choose the most effective choice. The Organizational Process Model underlines government behavior as output of wide organization functioning which has standardize pattern. Bureaucracy Politics Model stresses the bargaining, pulling and hauling among principal participants (Allison, 1969). Allison is not mention uncertainty as notably, however his explanation shows us how the US government was proceeding decision making under uncertainty information in the critical time with unknown responses from the Soviet Union authority.

\section{Cognitive and behavior approach: are they definitely separated or overlapped in certain features?}

Literature studies in decision making under uncertainty highlight two main perspectives which is mostly describes, either partially or collectively, in academic article namely cognitive and behavior. Cognitive school of thought is characterized as said by Klein \& Militello (2004) "goes beyond the behavioral decision making and encompasses a number of key elements that distinguish the expert from the novice, which include mental models, perceptual skills, sense of typicality, (Allen, 1977; Augier, 2001; Jones, 1999) routines, and declarative knowledge" (Alison et al., 2015: 296). Researches in rationality, analyzing choice, heuristics process, and knowledge themes often include in this group. On contrary, behavior research in decision making discusses about procedure, preferences, making executive choice, and action execution (Alison et al., 2015: 295).The core findings of this study is shown in table 1 and 2.

Table 1. Studies about decision making under uncertainty from cognitive perspectives

\begin{tabular}{|l|l|}
\hline \multicolumn{1}{|c|}{ Sub-perspectives } & \multicolumn{1}{c|}{ Studies and scholars } \\
\hline $\begin{array}{l}\text { Information and how to } \\
\text { process it }\end{array}$ & $\begin{array}{l}\text { a. Information gaps theory (Loewenstein as cited by van } \\
\text { Dijk \& Zeelenberg, 2007); } \\
\text { b. Bounded rationality (Allen, 1977; Augier, 2001; Jones, } \\
\text { 1999); } \\
\text { c. Bias, belief, and past-experiences (Morgan, Fischhoff, } \\
\text { Bostrom, \& Atman, 2002 as cited by Whitmer, Sims, \& } \\
\text { Torres, 2017). }\end{array}$ \\
\hline Heuristics & a. To do nothing ('t Hart, Rosenthal, \& Kouzmin, 1993; \\
\hline
\end{tabular}




\begin{tabular}{|c|c|}
\hline Sub-perspectives & \multicolumn{1}{c|}{ Studies and scholars } \\
\hline & Alison et al., 2015) \\
& b. Non-decision ('t Hart et al., 1993; Sobradelo et al., \\
& 2015) \\
& c. Delay implementing choice (Eyre, 2008 \& van Heuvel, \\
& 2012 in Alison et al., 2015) \\
& d. Availability heuristics (Tversky \& Kahneman, 1974) \\
\hline
\end{tabular}

Source: synthesizing from the literatures, 2018

Table 1 depicts the scholars' studies in decision making under uncertainty from cognitive point of view which is elaborated from two subdivision: first, it talks about information and ways of processing the information; secondly, it is pertaining to heuristics, which is in a simple word refers to belief (Tversky \& Kahneman, 1974). People tend to search information to fulfill their curiosity. Loewenstein (1994) assumes that curiosity is driven by perception of knowledge gap, however the accuracy of information to minimize the gap depends on the other ambiance of information set. When curiosity about problems is faced to a piece of information, it just serves a little insight, does not cover problem entirely which will determine decision making process and the outcome expected.

Decision maker in practice does not comprehensively rational. In spite of their effort to list every alternatives of a problem then calculate the consequences embedded to each alternative, they constraint by either individual or institutional cognitive capacity in processing information (Frederickson, Smith, Larimer, \& Licari, 2012: 172). Bounded rationalist argues the fundamental mature of uncertain affect cognitive process, then influence choice and decision outcome (Jones, 2003: 398). Allen (1977: 84) underlines decision maker's limited ability to perceive and understand, that makes them choose solution immediately available.

Bias has become the common procedure in real world decision whose probabilities hard to predict precisely. Experience contributes to shape bias; when person experiences emergency situation, they tend to belief that similar emergency situation more likely happen in the future (Whitmer et al., 2017: 358). Belief system informs person about action to do in emergency. It constructs how experience, bias, and belief involve in uncertainty or emergency decision making.

Cognitive bias derives from reliance on judgmental heuristics. Uncertain situation urges decision maker employ heuristics which often assume as an effective strategy (Tversky \& Kahneman, 1974: 1131). Since decision maker does not calculated risk in their competence, they will concentrate to certain limited field they known better (Heath \& Tversky, 1991). This explains why decision maker plays in known area and relies on familiar subject. 't Hart et al., (1993: 25-26) mention man-made calamity in Heizel Stadium of the 1985 European Foot Ball Final which was ended by tragedy could not handle by Belgian authority. The Belgian government and police department shaped non-decision act during the crisis which reaped worldwide critics. In this case, actors might be continued to avoid choice due to domain-specific expertise and macrocognition distribute in sociotechnical teams. The most experience actor sometimes relies on cognitive heuristics that suggest he/she to do nothing when no clear solution available for the problem (Alison et al., 2015: 296-297). 
Table 2. Studies about decision making under-uncertainty in behavior perspective

\begin{tabular}{|c|c|}
\hline Sub-perspectives & Studies and scholars \\
\hline Procedure & $\begin{array}{l}\text { a. Theoretical and informal model (Allen, 1977; } \\
\text { Nathanson, 1991) } \\
\text { b. Deterministic, probabilistic, and informational phase } \\
\text { Kaufman \& Thomas, 1977; Thomas \& Samson, } 1986 \text { in } \\
\text { Sobradelo et al., 2015). }\end{array}$ \\
\hline Preferences & $\begin{array}{l}\text { a. Communicating belief consonance (Golman, } \\
\text { Loewenstein, Moene, \& Zarri, 2016) } \\
\text { b. Functional perspective at lower level (Nohrstedt, 2013). }\end{array}$ \\
\hline Execution of action & a. Surprise management (Farazmand, 2017) \\
\hline
\end{tabular}

Source: synthesizing from the literatures, 2018

Researches in decision making under uncertainty from the perspective of behavioral approach can be divided into three sub-divisions: procedure, preference, and execution of action. Rational scholars think that decision making depends on specific steps and process for making choice; so that it becomes important to define means and ends of decision (Frederickson et al., 2012: 170). On contrary, Cyert and March in their behavioral theory of organization is simplifying procedures mentioned by rationalist by sharing sub-problem into sub-unit to allow the sub-unit employ local rationality. These process also apply in uncertainty situation where they reduce uncertainty through negotiating the impact and pressing the problems (Allen, 1977: 85-86). Procedures usually focus on scenario for possible behavior taken at the emergency moment. Prone community members are provided an evacuation choice even though the decision maker has no framework related to shortcoming effects of the evacuation decision has taken (Sobradelo et al., 2015: 980).

Having accurate preferences has considered as a right step in making decision. Incomplete preference for some reasons will lead decision maker to formulate 'precise guess' (Ok, Ortovela, Riella, 2012: 1791). Golman et al., (2016) point out communicating and sharing belief as a possible technique to explain phenomena that contribute to preference and knowledge. Maintain consonance open a chance to discuss different ideas and perspectives among decision makers. A little difference in belief could cause great discomfort then culminate to conflict. Stakeholders with different belief and interest will interpret evidence differently (Nohrstedt, 2013: 966). Sabatier and Jenkins-Smith (1999) add opinion to Golman's about importance of setting basic strategies amidst actors for achieving core values.

When the decision maker ended with decision outcome, prone communities await them to execute action. Under uncertainty condition, there is a tendency to act flexible and take improvisation (Nohrstedt, 2013: 976). Reflecting to Katrina crisis, Farazmand (2017) offers a new way of mind set and skill beyond the comprehension routine environment of governance and administration mostly runs called surprise management. It requires critical opportunities to practice surprise management in order to possess quality of adaptive and hyper-flexibility at the moment of emergency. 
Research findings explain that both cognitive and behavior shares their role relating to procedure which they called as heuristics in cognitive approach. When heuristic in cognitive terms interpreted as shortcut often used by decision making in uncertainty situation by recalling their belief, past and similar experiences to a moment they are facing; it also categorizes as informal decision making. At the moment level of improvisation increases, behavior associated to cognitive also strongly improves. It suggest the prominence of conventional behavior coupled with cognitive process; improvised behavior are linked to more explicit reasoning process (Mendonça, Webb, Butts, \& Brooks, 2004).

In the case of cognitive limitation, Lowenstein sees that "curiosity may induce people to engage in behaviors that go against their best interest." In the other words, curiosity implies to impulsive behavior, such as regret and disappointment (van Dijk \& Zeelenberg, 2007). Studies conduct by Josephs, Larrick, Steele, \& Nisbett (1992) shows that person attributed with high self-esteem tend to expose him/herself to information that may be ended to unpleasant outcome that person with low self-esteem. In sum, cognitive perspective and behavior could not be separated definitely. They tend to build a series activity or be overlapped in aspect(s).

\section{Research limitation}

This article states some limitations since this is an ongoing process as a part of author dissertation, particularly in the area related to literatures and span of analysis. Author has been collecting and reading dozens articles on decision making under uncertainty, ambiguity, and risk topics. Still, limited numbers of articles specifically explore this topic from the public administration point of view. Available articles tend to explain decision making under uncertainty from policy perspective which is differs from public administration in certain parts.

\section{Conclusion}

Studies in decision making under uncertainties tends to be approached from cognitive and behavior perspective. Cognitive perspective has been studied pertain to information processing and heuristics, while behavior stream elaborated from procedure aspect, preference, and execution of action. This research shows either cognitive or behavior perspective are not definitely separated, they apparently becomes a serial activity or overlapped in certain aspects, in this case is heuristics and procedure. Despite this study aims to explore decision making under uncertainty from public administration point of view, it is a constraint to find appropriate articles. Hence, author should be elaborated from another field, i.e. economics, management, and natural science.

\section{Acknowledgement}

This article is presented through promotion from Department of Public Policy and Management Faculty of Social and Political Science, Universitas Gadjah Mada. Author is also thankful for the guidance of Professor Agus Pramusinto and Bevaola Kusumasari, PhD. 


\section{References}

't Hart, P., Rosenthal, U., \& Kouzmin, A. (1993). Crisis decision making: The centralization thesis revisited. Administration \& Society, 25(1), 12-45. https://doi.org/10.1177/009539979302500102

Alison, L., Power, N., van den Heuvel, C., Humann, M., Palasinksi, M., \& Crego, J. (2015). Decision inertia: Deciding between least worst outcomes in emergency responses to disasters. Journal of Occupational and Organizational Psychology, 88(2), 295-321. https://doi.org/10.1111/joop.12108

Allen, D. (1977). A Review of Process Theories of Decision Making. Management Learning, 8(2), 79-94. https://doi.org/10.1177/135050767700800204

Allison, G. T. (1969). Conceptual Models and the Cuban Missile Crisis. The American Political Science Review, 63(3), 698-718.

Allison, G. T. (1971). Essence of Decision Explaining the Cuban Missile Crisis. Boston: Little, Brown and Company.

Augier, M. (2001). Simon Says: Bounded Rationality Matters: Introduction and Interview. Journal of Management Inquiry, 10(3), 268-275. https://doi.org/10.1177/1056492601103010

Bailey, S. K. (2010). The Role of Personality on Decision Making Under Uncertainty.

Boin, A., Hart, P. T., Mcconnell, A., \& Preston, T. (2010). Leadership style, crisis response and blame management: The case of hurricane katrina. Public Administration, 88(3), 706-723. https://doi.org/10.1111/j.1467-9299.2010.01836.x

de Kort, I. A. T., \& Booij, M. J. (2007). Decision making under uncertainty in a decision support system for the Red River. Environmental Modelling and Software, 22(2), 128136. https://doi.org/10.1016/j.envsoft.2005.07.014

E. Ok, P. Ortovela, G. R. (2012). Incomplete Preferences Under Uncertainty: Indecisiveness in Beliefs versus Tastes. Econometrica, 80(4), 1791-1808. https://doi.org/10.3982/ECTA8040

Faraji-Rad, A., \& Pham, M. T. (2017). Uncertainty increases the reliance on affect in decisions. Journal of Consumer Research, 44(1), 1-21. https://doi.org/10.1093/jcr/ucw073

Farazmand, A. (2017). Learning from the Katrina Crisis: A Global and International Perspective with Implications for Future Crisis Management Author ( s ): Ali Farazmand Source: Public Administration Review, Vol . 67 , Special Issue on Administrative Failure in the Wake of , 67, 149-159.

Frederickson, H. G., Smith, K. B., Larimer, C. W., \& Licari, M. J. (2012). The Public Administration Theory Primer. https://doi.org/10.5860/CHOICE.41-2423 
Golman, R., Loewenstein, G., Moene, K. O., \& Zarri, L. (2016). The Preference for Belief Consonance. Journal of Economic Perspectives, 30(3), 165-188. https://doi.org/10.1257/jep.30.3.165

Grothe-Hammer, M., \& Berthod, O. (2017). The programming of decisions for disaster and emergency response: A Luhmannian approach. Current Sociology, 65(5), 735-755. https://doi.org/10.1177/0011392116640592

Heath, C., \& Tversky, A. (1991). Preferences and Beliefs: Ambiguity and Competence in Choice under Uncertainty. Journal of Risk and Uncertainty, 4(1), 5-28. https://doi.org/10.1007/BF00057884

Jones, B. D. (1999). Bounded Rationality. Annual Review of Political Science, 2(1), 297-321. https://doi.org/10.1146/annurev.polisci.2.1.297

Jones, B. D. (2003). Bounded Rationality and Political Science: Lessons from Public Administration and Public Policy. Journal of Public Administration Research \& Theory, 13(4), 395-412. https://doi.org/10.1093/jopart/mug028

Josephs, R. A., Larrick, R. P., Steele, C. M., \& Nisbett, R. E. (1992). Protecting the self from the negative consequences of risky decisions. Journal of Personality and Social Psychology, 62(1), 26-37. https://doi.org/10.1037/0022-3514.62.1.26

Loewenstein, G. (1994). The Psychology of Curiosity: A Review and Reinterpretation. Psychological Bulletin, 116(1), 75-98.

Madani, K., Read, L., \& Shalikarian, L. (2014). Voting Under Uncertainty: A Stochastic Framework for Analyzing Group Decision Making Problems. Water Resources Management, 28(7), 1839-1856. https://doi.org/10.1007/s11269-014-0556-8

Mendonça, D., Webb, G., Butts, C., \& Brooks, J. (2004). Cognitive Correlates of Improvised Behaviour in Disaster Response : the Cases of the Murrah Building and the World Trade Center, 22(4).

Nathanson, S. L. (1991). Kennedy and the Cuban Missile Crisis: on the Role of Moral Reasons in Explaining and Evaluating Political Decision-Making. Journal of Social Philosophy, 22(2), 94-108.

Nohrstedt, D. (2013). Advocacy coalitions in crisis resolution: Understanding policy dispute in the European volcanic ash cloud crisis. Public Administration, 91(4), 964-979. https://doi.org/10.1111/padm.12003

Reggiani, P., \& Weerts, A. H. (2008). A Bayesian approach to decision-making under uncertainty: An application to real-time forecasting in the river Rhine. Journal of Hydrology, 356(1-2), 56-69. https://doi.org/10.1016/j.jhydrol.2008.03.027

Riccucci, N. M. (2010). Public administration: traditions of inquiry and philosophies of knowledge. Washington, D.C.: Georgetown University Press.

Sayegh, L., Anthony, W. P., \& Perrewé, P. L. (2004). Managerial decision-making under 
crisis: The role of emotion in an intuitive decision process. Human Resource Management Review, 14(2), 179-199. https://doi.org/10.1016/j.hrmr.2004.05.002

Sobradelo, R., Martí, J., Kilburn, C., \& López, C. (2015). Probabilistic approach to decisionmaking under uncertainty during volcanic crises: retrospective application to the E1 Hierro (Spain) 2011 volcanic crisis. Natural Hazards, 76(2), 979-998. https://doi.org/10.1007/s11069-014-1530-8

Su, H.-T., \& Tung, Y.-K. (2014). Multi-criteria decision making under uncertainty for flood mitigation. Stochastic Environmental Research and Risk Assessment, 28(7), 1657-1670. https://doi.org/10.1007/s00477-013-0818-7

Sun, B., Ma, W., \& Zhao, H. (2016). An approach to emergency decision making based on decision-theoretic rough set over two universes. Soft Computing, 20(9), 3617-3628. https://doi.org/10.1007/s00500-015-1721-6

Tuckett, D., Mandel, A., Mangalagiu, D., Abramson, A., Hinkel, J., Katsikopoulos, K., ... Wilkinson, A. (2015). Uncertainty, Decision Science, and Policy Making: A Manifesto for a Research Agenda. Critical Review, 27(2), 213-242. https://doi.org/10.1080/08913811.2015.1037078

Tversky, A., \& Kahneman, D. (1974). Judgment under Uncertainty : Heuristics and Biases Linked references are available on JSTOR for this article : Judgment under Uncertainty: Heuristics and Biases. Science, 185(4157), 1124-1131. https://doi.org/10.1126/science.185.4157.1124

van Dijk, E., \& Zeelenberg, M. (2007). When curiosity killed regret: Avoiding or seeking the unknown in decision-making under uncertainty. Journal of Experimental Social Psychology, 43(4), 656-662. https://doi.org/10.1016/j.jesp.2006.06.004

Wenzelburger, G., König, P. D., \& Wolf, F. (2017). Policy Theories in Hard Times? Assessing the Explanatory Power of Policy Theories in the Context of Crisis. Public Organization Review. https://doi.org/10.1007/s11115-017-0387-1

Whitmer, D. E., Sims, V. K., \& Torres, M. E. (2017). Assessing Mental Models of Emergencies Through Two Knowledge Elicitation Tasks. Human Factors, 59(3), 357376. https://doi.org/10.1177/0018720816672117 